\title{
Разработка и изготовление микросборок на многослойной керамике
}

\author{
А. Щербина
}

УДК 621.3.049.76 | ВАК 05.27.01

\begin{abstract}
При создании высокоинтегрированных сборок и модулей для подложек используют материалы с высокой теплопроводностью, которые позволяют эффективно рассеивать избыточное тепло. В силовой электронике и микроэлектронике применяют керамические подложки, которые служат основой для нанесения тонких или толстых пленок при формировании металлизации и пленочных компонентов. В АО "ТЕСТПРИБОР» освоены технологии изготовления однослойных и многослойных подложек из керамики на основе оксида алюминия, нитрида алюминия и оксида бериллия, которые характеризуются высокими теплопроводностью и механической прочностью, низкими коэффициентом теплового расширения и диэлектрическими потерями. В качестве примера применения данных технологий рассмотрим разработку корпуса для микросборки на основе этих материалов.
\end{abstract}

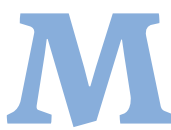
икросборка представляет собой часть схемы DC/ DC-преобразователя напряжения (рис. 1) Основное требование к ее корпусу - обеспечить отвод тепла, выделяемого на полевых транзисторах (VT2 и VT3), каждый из которых рассеивает до 4 Вт мощности.

Условия работы микросборки и кристаллов транзисторов:

- микросборка используется в условиях вакуума;

- максимальная температура кристаллов не должна превышать $125^{\circ} \mathrm{C}$ при работе изделия в условиях предельно допустимой температуры, составляющей $65^{\circ} \mathrm{C}$.

При отработке схемы применялись корпусные транзисторы в корпусе КТ-94. Для микросборки использовались кристаллы транзисторов размером 5,6×5,0 мм и 7,33×7,31 мм, параметры которых приведены в табл. 1.

На текущем этапе развития производства в АО "ТЕСТПРИБОР» в качестве материала подложек можно

АО «ТЕСТПРИБОР», начальник отдела развития и технической поддержки. использовать оксид алюминия с чистотой 99,5\% или нитрид алюминия. Параметры материалов приведены

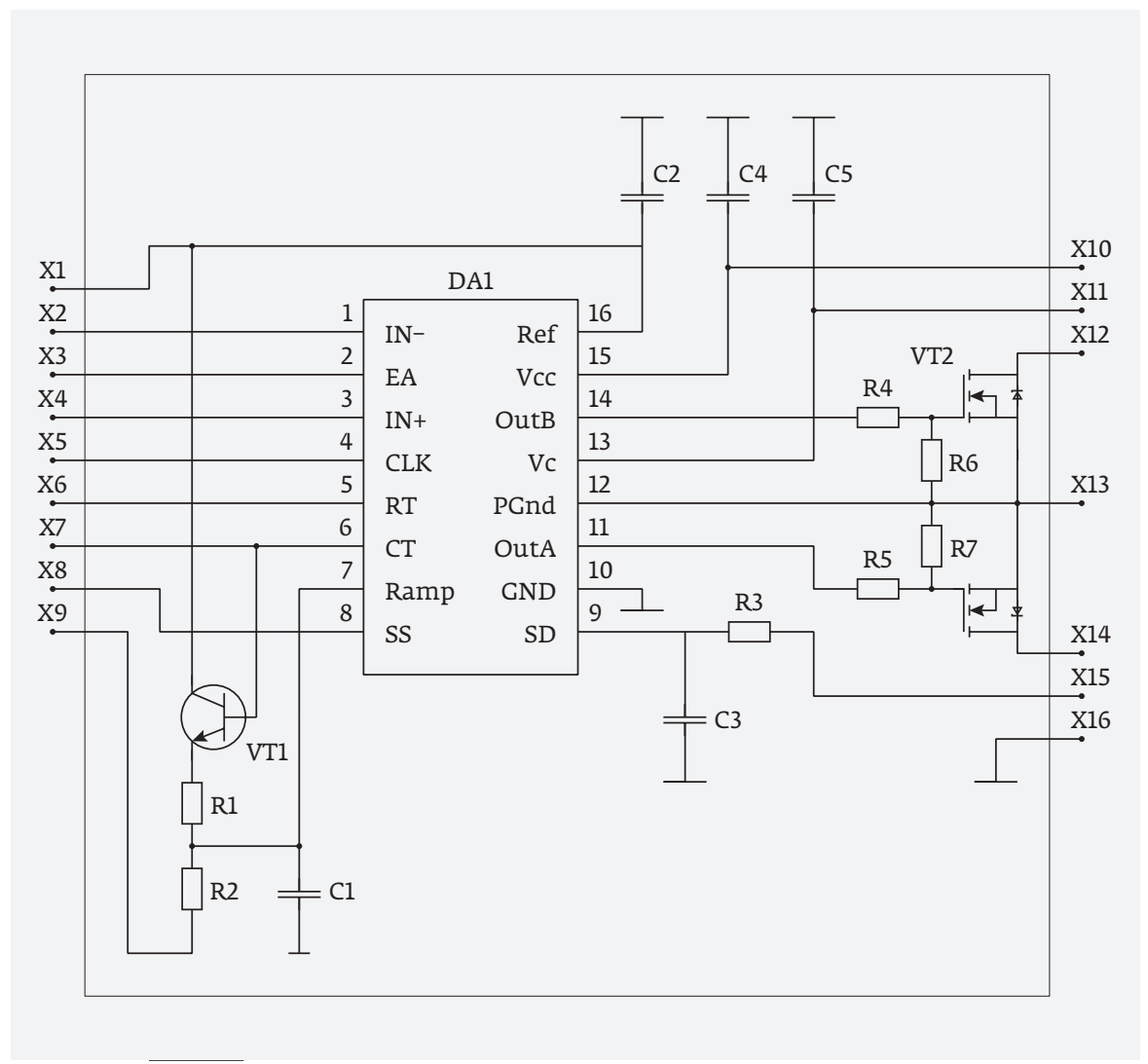

Рис. 1. Электрическая принципиальная схема микросборки 
Таблица 1. Параметры полевых транзисторов

\begin{tabular}{|c|c|c|c|c|c|c|}
\hline Наименование & $\mathrm{U}_{\mathrm{ch}}, \mathrm{B}$ & $\mathrm{I}_{\mathrm{c}}, \mathrm{A}$ & $\mathrm{R}_{\text {Cи }}, \mathrm{OM}$ & $\mathrm{C}_{11}, \mathrm{H} \Phi$ & Исполнение & Габариты, мм \\
\hline 2П768ח92 & 400 & 11 & 0,42 & 1,9 & Корпус КТ-94 & $11,6 \times 16,0$ \\
\hline $2 \Pi 768 \Pi-5$ & 400 & 11 & 0,42 & 1,9 & Кристалл & $5,6 \times 5,0$ \\
\hline 2П794В92 & 400 & 18 & 0,2 & 3,3 & Корпус КТ-94 & $11,6 \times 16,0$ \\
\hline 2П794В-5 & 400 & 18 & 0,2 & 3,3 & Кристалл & $7,33 \times 7,31$ \\
\hline
\end{tabular}

Таблица 2. Параметры керамики

\begin{tabular}{lcc} 
материал & Оксид алюминия $(99,5 \%)$ & Нитрид алюминия \\
Химическая формула & $\mathrm{Al}_{2} \mathrm{O}_{3}$ & $\mathrm{AlN}$ \\
\hline Температура плавления, ${ }^{\circ} \mathrm{C}$ & 2072 & $2397-2507$ \\
\hline Максимальная рабочая температура, ${ }^{\circ} \mathrm{C}$ & 1750 & $1027-1727$ \\
\hline Коэффициент теплового расширения, $1 \cdot 10^{-6}{ }^{\circ} \mathrm{C}^{-1}$ & $7-8,4$ & $4,3-9$ \\
\hline Удельная теплоемкость, Дж/(кг $\cdot \mathrm{K})$ & 880 & $740-820$ \\
\hline Теплопроводность, Вт $/ \mathrm{M}^{2} \cdot \mathrm{K}$ & $25,5-35$ & $60-177$ \\
\hline Диэлектрическая проницаемость & 9,8 & $8,3-9,3$ \\
\hline Объемное удельное сопротивление, Ом $\cdot \mathrm{CM}$ & $>1 \cdot 10^{14}$ & $>1 \cdot 10^{14}$ \\
\hline
\end{tabular}

в табл. 2. Толщина одного слоя керамики после обжига составляет 0,25 мм.

Рассмотрим, как отводится тепло от кристалла, смонтированного на керамической подложке из оксида алюминия и нитрида алюминия, при условии, что тепло с подложки может рассеиваться только с основания корпуса микросборки на корпус изделия, куда устанавливается микросборка.

Один из критериев определения достаточной площади для отвода тепла от кристалла - температура в установившемся режиме, которая не должна превышать $80-85^{\circ} \mathrm{C}$ при температуре окружающей среды $20^{\circ} \mathrm{C}$.

Кристалл, размером 5,6×5,0 мм, установленный в центр керамической подложки на основе оксида алюминия, размером 80,0 × 80,0 мм, нагревается до температуры выше $140{ }^{\circ} \mathrm{C}$ (рис. 2). При этом тепло не рассеивается по площади подложки, что не соответствует требованиям. Аналогично и для второго кристалла, размером $7,33 \times 7,31 \mathrm{~mm}$

Кристалл, размером 5,6×5,0 мм, установленный в центр керамической подложки из нитрида алюминия,

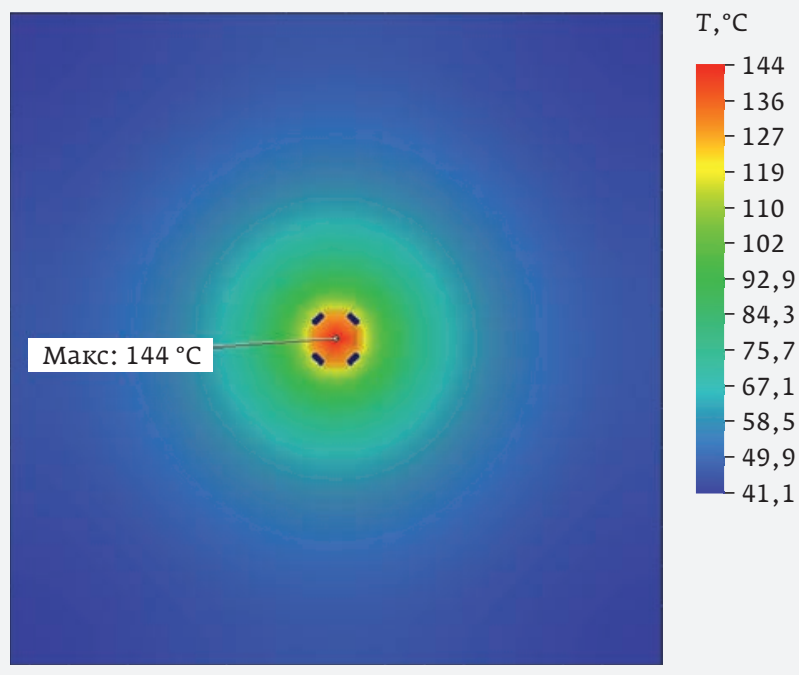

Рис. 2. Распределение тепла на подложке из $\mathrm{Al}_{2} \mathrm{O}_{3}$ размером 80,0×80,0 мм 


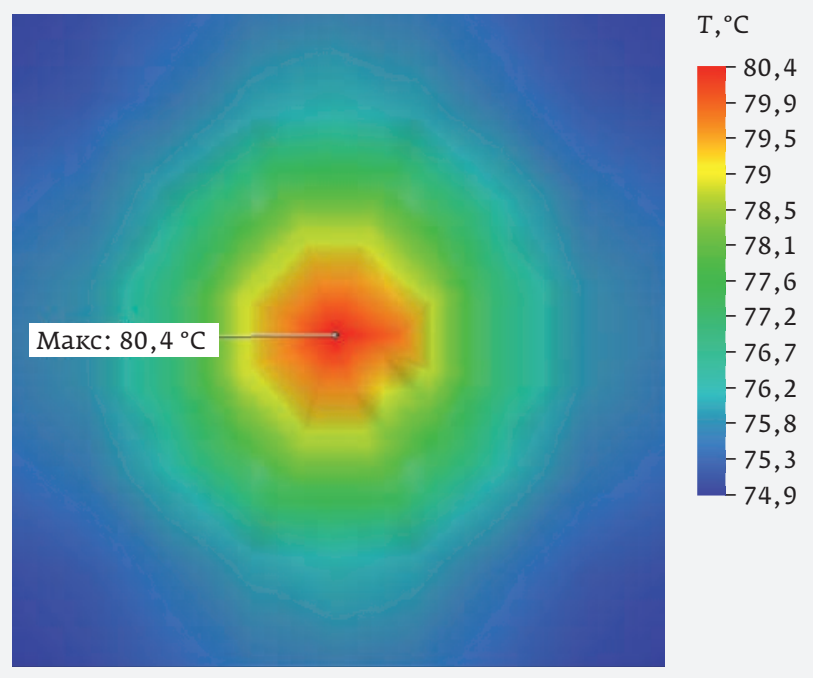

Рис. 3. Распределение тепла на подложке из AlN размером $18,0 \times 18,0 \mathrm{Mm}$

размером 18,0×18,0 мм, нагревается до 80,4 ${ }^{\circ} \mathrm{C}$, что соответствует требованиям (рис. 3). Расчет температуры второго кристалла, размером 7,33×7,31 мм, установленного на такую же подложку, показал результат 78, 9 C, что также обеспечивает выполнение требований задания.

На рис. 4 представлен расчет температуры кристаллов, установленных на керамическую подложку, размером 36,0×18,0 мм, при работе двух транзисторов одновременно. Максимальная температура нагрева кристалла не изменилась.
Исходя из полученных результатов был выбран корпус с габаритами 36,0 ×18,0 мм.

Одна из технологий, предлагаемыхАО «ТЕСТПРИБОР»,производство изделий из высокотемпературной керамики (НТСC). Основное отличие высокотемпературной керамики от низкотемпературной (LTCC) - более высокая температура спекания слоев керамических плат: 1500-1600 C (для LTCC - менее $1000^{\circ} \mathrm{C}$ ).

Преимущества технологии НТСС:

- малые допуски на размеры - благодаря низкому коэффициенту теплового расширения обеспечивается повышенная стабильность размеров корпусов;

- коэффициент теплового расширения (КТР) высокотемпературной керамики достаточно близок к КТР кремния, что позволяет монтировать кристаллы непосредственно на керамическое основание;

- высокие диэлектрические и тепловыехарактеристики корпусов: в зависимости от используемой марки керамики электрическая прочность варьируется в пределах от 45 до 60 кB / мм, тангенс угла диэлектрических потерь (tg $\delta$ ) - от 0,006 до 0,021, а диэлектрическая проницаемость ( $\varepsilon$ ) - от 6 до 10 в гигагерцовом диапазоне частот;

- возможность создания многослойных герметичных керамических плат: высокотемпературная керамика отличается плотной структурой, после спекания многослойные керамические модули становятся монолитными;

- хорошее заполнение переходных отверстий и линий металлизации в плате вольфрамовой или молибденовой пастой;

- высокая твердость используемых керамических материалов.
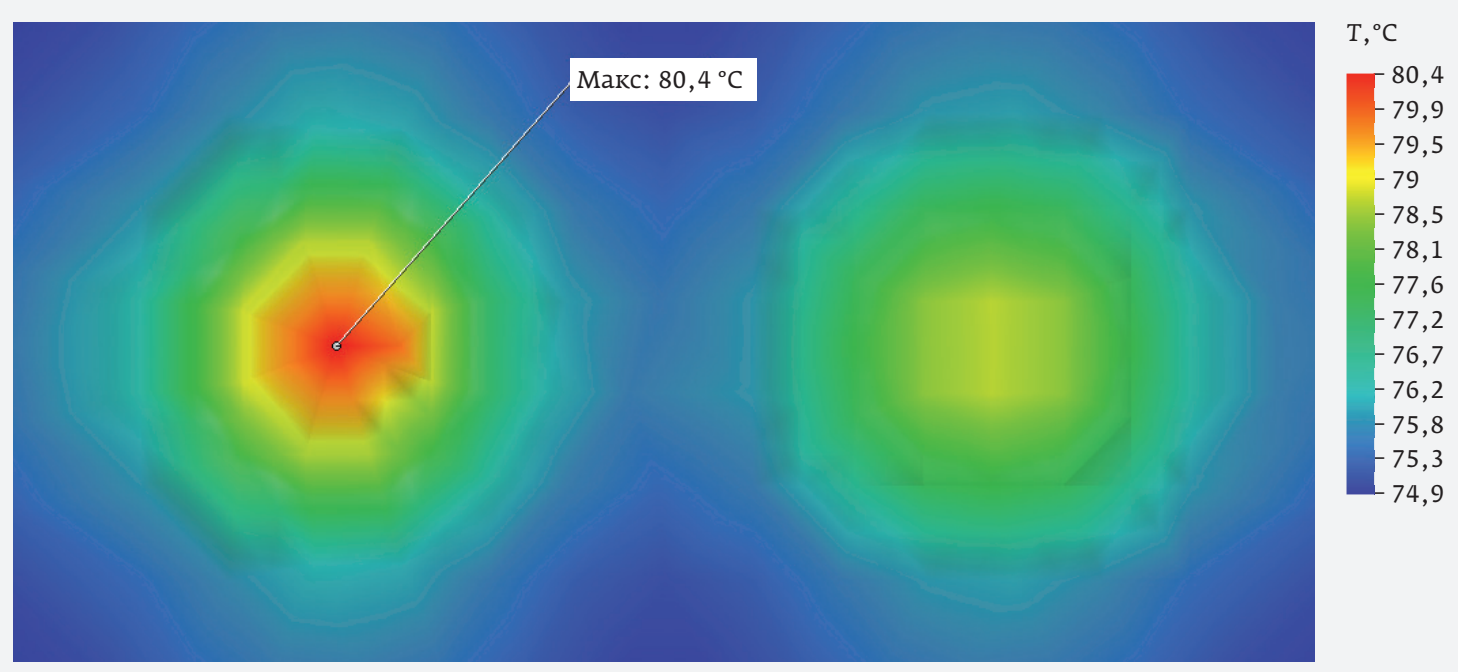

Рис. 4. Распределение тепла от двух кристаллов на подложке из AlN размером 36,0×18,0 мм 


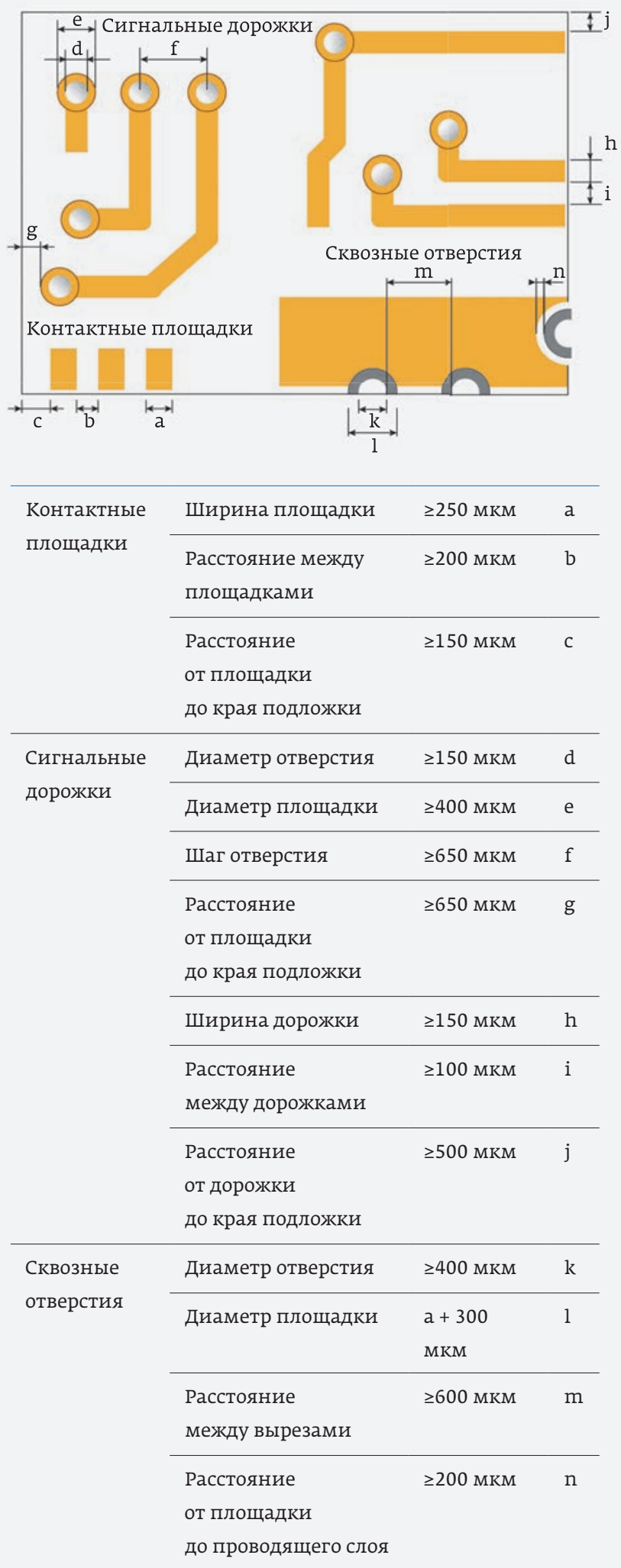

Рис. 5. Технологические возможности производства АО «ТЕСТПРИБОР»

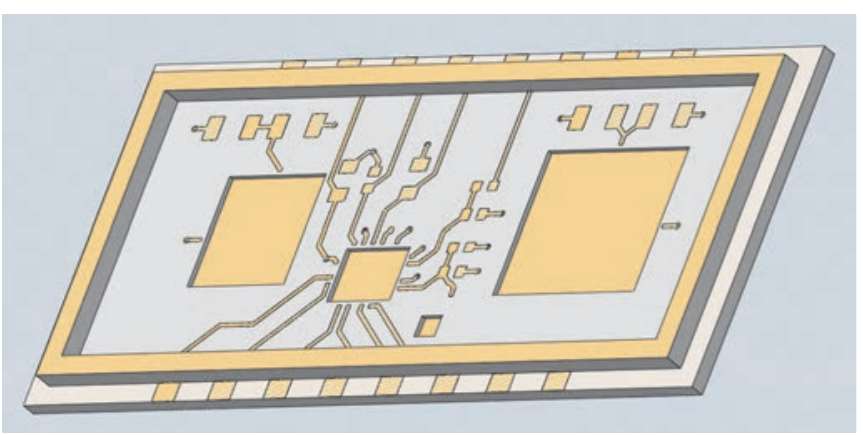

Рис. 6. Внешний вид корпуса

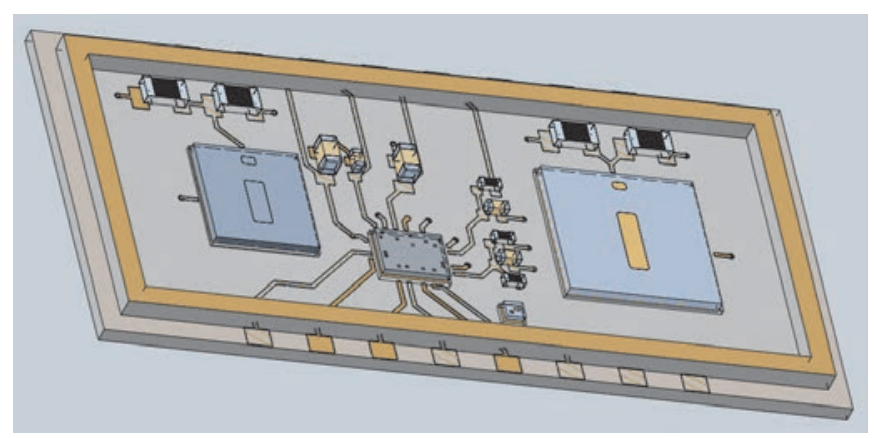

Рис. 7. Внешний вид микросборки с установленными компонентами

Гарантированные технологические возможности производства АО «ТЕСТПРИБОр» приведены на рис. 5. На основе указанных норм был разработан корпус. Поскольку площадь для отвода тепла под кристаллом довольно большая, плотность монтажа микросборки получилась относительно низкой.

Внешний вид разработанного корпуса и микросборки с установленными компонентами показаны на рис. 6 и 7 соответственно. Микросборка содержит четыре кристалла и 12 пассивных SMD-компонентов. Преимущества микросборок (в том числе разработанной) состоят в том, что изделия занимают меньше места, имеют меньшую массу по сравнению со схемой, собранной из корпусных дискретных компонентов. Это важно для систем, предназначенных, например, для применения в космосе. Для более функциональных и крупных сборок применяют многоуровневое расположение компонентов, что позволяет упростить защиту отдельных элементов от радиации и уменьшить массу изделия по сравнению со сборкой с общим защитным экраном.

У АО "ТЕСТПРИБОР» есть возможность разработкИ и изготовления микросборок на многослойной керамике из $\mathrm{Al}_{2} \mathrm{O}_{3}$ и AIN по требованиям заказчика. Компания планирует продолжать совершенствовать производственные технологические процессы. 


\section{害ТЕСТПРИБОР}

\section{Высококачественные покрытия $\mathrm{Ni}, \mathrm{Au}$ произво Аства АО «ТЕСТПРИБОР»}

Различные метамиические покрытия, выполненные электрохимическим, химическим и Аругими способами находят активное применение при произво $\Delta$ стве широкого спектра изАелий микроэлектроники.
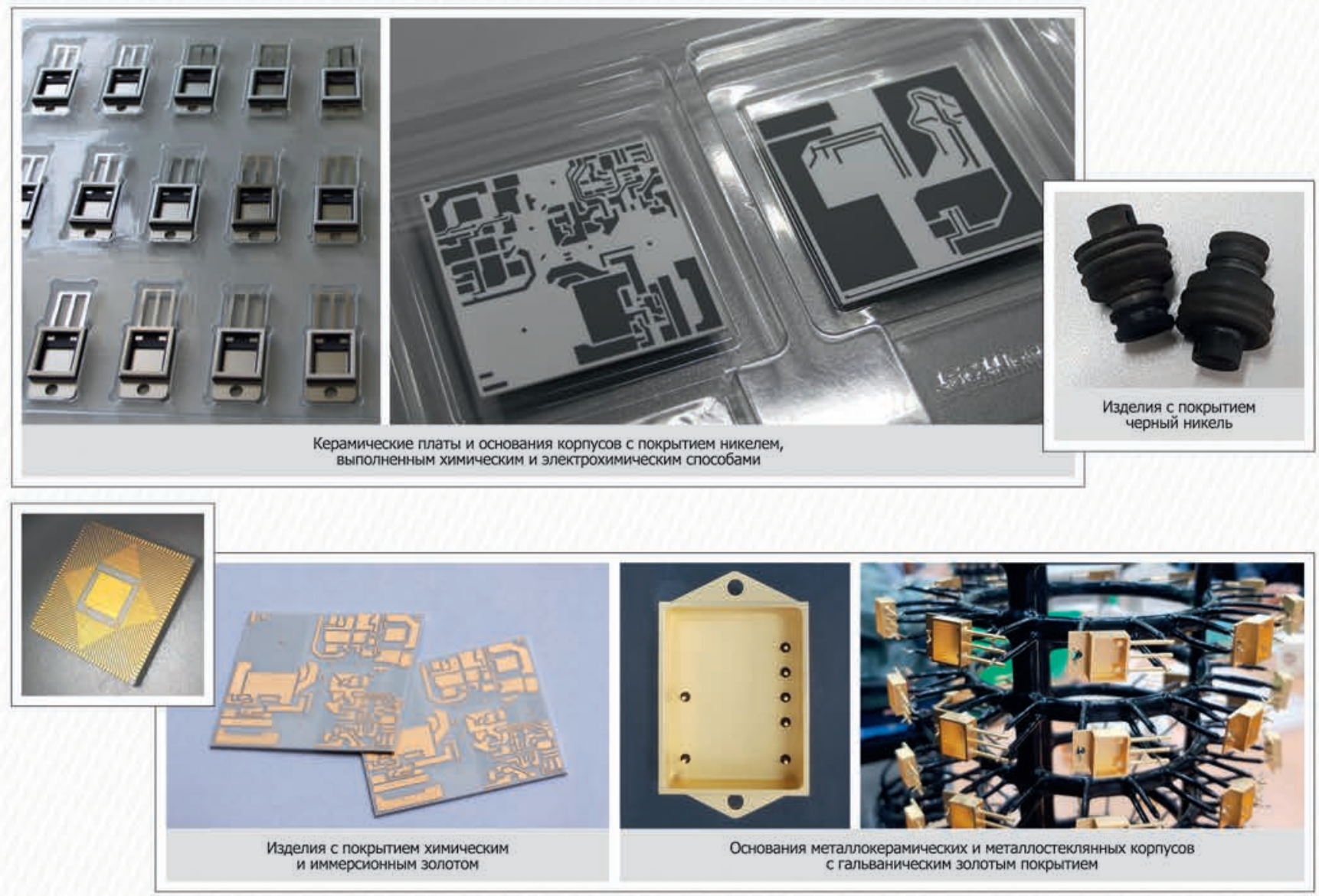

Производство компании «ТЕСТПРИБОР» в рамках освоения различного рода экспериментальной и серийной продукции владеет следующими технологиями нанесения покрытий:

- электрохимическое никелирование из растворов различных составов: толщина слоя покрытия до 30 мкм;

- электрохимическое никелирование сплавом никель-фосфор: толщина слоя покрытия до 30 мкм;

- химическое никелирование сплавами никель-фосфор, никель-бор: гарантированная толщина покрытия до 10 мкм
- электрохимическое золочение: толщина покрытия до 10 мкм

- химическое и иммерсионное золочение - толщина покрытия, нанесенного химическим способом, от 0,5 до 2,5 мкм, толщина слоя иммерсионного покрытия до 0,15 мкм

- «черный никель» 
Важным фактором успеха при выполнении покрытия электрохимическим методом является грамотно спроектированная оснастка, позволяющая:

- наносить покрытие на большое количество изделий с разницей в толщине от изделия к изделию не превышающей 1-2\% внутри партии и не более 5\% по поверхности одного изделия в зависимости от его формы и особенностей топологии;

- наносить покрытие разной толщины на изолированные друг от друга части изделия, что особенно важно в случае нанесения золотого покрытия и позволяет снизить себестоимость детали за счет снижения расхода золота на покрытие тех участков, которые удаляются в процессе монтажа корпуса в прибор при сборке конечного устройства, либо выполнить частичное покрытие только технологически важных участков;

- минимизировать размер паразитных точек контакта, либо устранять их методом локального покрытия;

- использовать химически стойкие материалы (нержавеющая сталь, полиэтилен, поливинилхлорид) для снижения рисков загрязнения растворов продуктами травления подвески.

\section{ПРИМЕРЫ ОРИГИНАЛЬНОЙ ОСНАСТКИ ДЛЯ ГАЛЬВАНИЧЕСКОГО ПОКРЫТИЯ, СПРОЕКТИРОВАННОЙ И ИЗГОТОВЛЕННОЙ АО «ТЕСТПРИБОР»:}

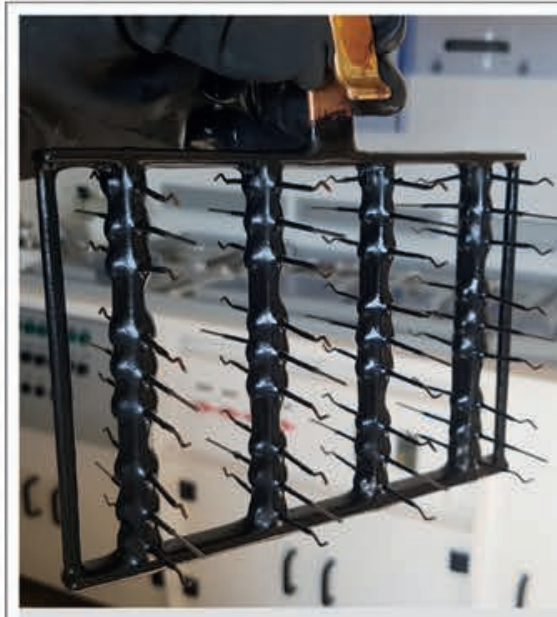

для лабораторной установки

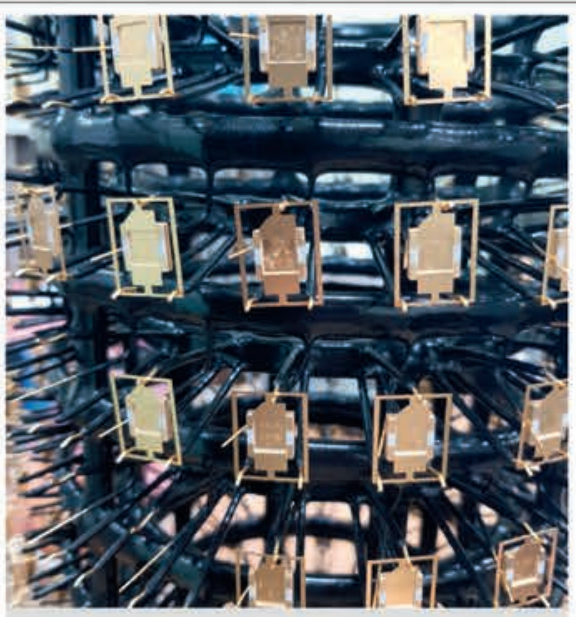

для частичного покрытия или нанесения для частично пори

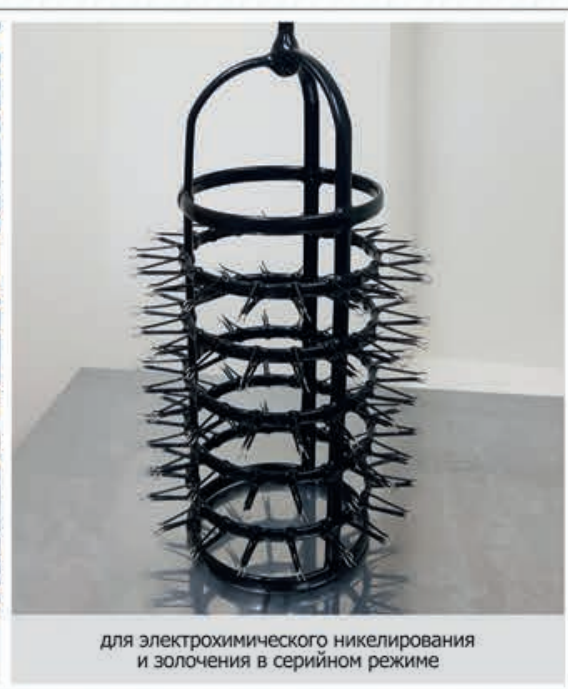

Высокое качество гальванических покрытий, выполненных на производстве АО «ТЕСТПРИБОР», обеспечено:

- специально спроектированным оборудованием и оснасткой, позволяющим получать повторяемость по толщине и характеристикам покрытий внутри партии и достигать равномерности покрытия на одном изделии настолько, насколько позволяют его геометрические характеристики.

- качеством используемых растворов и постоянством технологических параметров, под четким контролем производственной лаборатории и инженерного персонала.
- грамотно подобранными составами, позволяющими наносить как классические покрытия, так и редко используемые при обычной практике - например, золотое покрытие, выполненное химическим способом до толщины более 2 мкм, что способствует осуществлению широкого спектра задач поставленных заказчиками компании.

- контролем качества изделий, производимым в несколько этапов по многим параметрам на $100 \%$ продукции, что снижает вероятность попадания бракованных изделий к заказчику. 